\title{
The Long-Term Cost to the UK NHS and Social Services of Different Durations of IV Thiamine (Vitamin B1) for Chronic Alcohol Misusers with Symptoms of Wernicke's Encephalopathy Presenting at the Emergency Department
}

\author{
Edward C. F. Wilson ${ }^{1}$ (D) George Stanley ${ }^{2} \cdot$ Zulfiquar Mirza $^{3}$
}

Published online: 30 December 2015

(c) The Author(s) 2015. This article is published with open access at Springerlink.com

\begin{abstract}
Background Wernicke's encephalopathy (WE) is an acute neuropsychiatric condition caused by depleted intracellular thiamine, most commonly arising in chronic alcohol misusers, who may present to emergency departments (EDs) for a variety of reasons. Guidelines recommend a minimum 5-day course of intravenous (IV) thiamine in at-risk patients unless WE can be excluded.

Objective To estimate the cost impact on the UK public sector (NHS and social services) of a 5-day course of IV thiamine, vs a 2- and 10-day course, in harmful or dependent drinkers presenting to EDs.

Methods A Markov chain model compared expected prognosis of patients under alternative admission strategies over 35 years. Model inputs were derived from a prospective cohort study, expert opinion via structured elicitation and NHS costing databases. Costs (2012/2013 price year) were discounted at $3.5 \%$.

Results Increasing treatment from 2 to 5 days increased acute care costs but reduced the probability of disease
\end{abstract}

Electronic supplementary material The online version of this article (doi:10.1007/s40258-015-0214-1) contains supplementary material, which is available to authorized users.

Twitter: @EdCFWilson.

Edward C. F. Wilson

ed.wilson@medschl.cam.ac.uk

1 Cambridge Centre for Health Services Research, University of Cambridge, Cambridge CB2 OSR, UK

2 Archimedes Pharma UK Ltd, South Oak Way, Green Park, Reading RG2 6UG, UK

3 West Middlesex University Hospital, Twickenham Road, Isleworth, Middlesex TW7 6AF, UK progression and thus reduced the expected net costs by GBP87,000 per patient (95\% confidence interval GBP19,300 to GBP172,300) over 35 years.

Conclusions Increasing length of stay to optimize IV thiamine replacement will place additional strain on acute care but has potential UK public sector cost savings. Social services and the NHS should explore collaborations to realise both the health benefits to patients and savings to the public purse.

\section{Key Points for Decision Makers}

Guidelines state that suspected Wernicke's encephalopathy should be treated with 5 days of IV thiamine.

Different admission strategies in at-risk patients were modelled.

Admissions of 5 instead of 2 days may reduce cost per patient by GBP87,000 over 35 years.

Every extra GBP1 spent in acute care is estimated to save GBP6 in future social care costs.

\section{Introduction}

Wernicke's encephalopathy (WE) is an acute neuropsychiatric condition caused by an initially reversible brain lesion due to 'overwhelming metabolic demands on cells with depleted intracellular thiamine' [1]. Autopsy studies estimate the prevalence of WE in the general population at 
between $0.4 \%$ and approximately $2 \%$, with lower rates in Western Europe and the higher rates observed in Australia [2-4]. Among chronic alcoholics the prevalence rises to $14 \%$ [5]. The diagnosis of affected patients before death has been reported to be as low as $5 \%$ [6], the acute mortality rate is around $20 \%[6,7]$, while approximately $75 \%$ of patients are left with permanent brain damage and disability [6, 7]. WE is most commonly seen in chronic alcohol misusers [8] who are deficient in dietary thiamine [9, 10]. The condition can be easily missed if not suspected, owing to the similarity of the symptoms to other alcohol-related effects (e.g. intoxication, abnormal gait and other neurological disorders or head trauma). Although factors predisposing to thiamine deficiency have been identified [11], ignoring these symptoms and signs can lead to loss of consciousness, coma and death [12].

No sensitive and robust screening tool that can be administered in acute care settings, such as emergency department (ED) consultations, is currently available. The classic signs of WE were originally described as a triad, comprising abnormal mental state, gait ataxia (uncoordinated movement) and ophthalmoplegia (paralysis/weakness of the muscles of the eye). Notably, however, all three symptoms are only seen in approximately $10-16.5 \%$ of cases $[1,6,13]$, thus reliance on the presence of the triad leads to under-diagnosis.

Depending on the severity of the illness at presentation, patients are typically seen first in the ED although diagnosis of WE can take place in a community setting via GP consultations, typically with subsequent referrals to acute or specialist care. Patients with WE present in a variety of ways, including with head injuries (e.g. skull fractures), vomiting, an inability to walk (resulting in falls), confusion, fits, infections or complications of chronic liver disease and dietary deficiencies $[11,12,14]$. In addition, they may present with a variety of psychiatric illnesses, necessitating a psychiatric assessment. Depending on clinical assessment [that may include laboratory investigations and computerised tomography (CT)] and after initial resuscitation in the ED, patients may be admitted under the appropriate specialist teams. For those departments with an alcohol nurse specialist, an assessment provides additional perspectives on diagnosis and appropriate treatment. A joint assessment with the liaison psychiatric team would be ideal for an holistic approach [15].

If untreated or inadequately treated, approximately $85 \%$ of patients with WE are at risk of developing the chronic form of the condition, Korsakoff's syndrome (KS), also known as Korsakoff's psychosis (KP), a mostly irreversible neuropsychiatric condition that often results in the patient being admitted to long-term care $[6,7,16]$. The acute and chronic stages together are referred to as Wernicke-Korsakoff syndrome (WKS).
Treatment is with parenteral vitamin supplements, specifically intravenous (IV) thiamine (vitamin $B_{1}$ ) [7]. Pabrinex ${ }^{\circledR}$ Intravenous High Potency Injection (Archimedes Pharma UK Ltd) is the only IV preparation of thiamine marketed in the UK and it is presented as two ampoules. Two or three pairs of ampoules are mixed with 50-100 $\mathrm{mL}$ saline and administered to the patient in one dose, preferably via a drip infusion over $30 \mathrm{~min}$, repeated every $8 \mathrm{~h}$ [17]. However, the duration of treatment is not specified in the Summary of Product Characteristics (SmPC) [17], and guidelines and hospital protocols on the optimal duration vary. The British National Formulary (BNF) recommends maintaining this dose for the first 2 days, reducing to one pair of ampoules daily for at least another 5 days or 'for as long as improvement continues' [18]. The National Institute for Health and Care Excellence (NICE) recommends a minimum 5-day course of parenteral administration unless WE can be excluded [19]. This guidance reflects the challenges of clinical assessment of WE, the limited evidence base and the limited window of opportunity for replenishment of thiamine in at-risk patients during contact with acute care settings.

Pressure on beds in the acute setting is also likely to affect the decision to admit a patient, especially where a definitive diagnosis of WE cannot be made. Whilst other aetiologies exist, the most common presentation is associated with chronic alcohol misuse $[1,6]$. Patients may be of no fixed abode and, once discharged, such patients are often lost to follow-up, unless they re-present at an ED in the future. It is reasonable to suppose that a patient who receives less than the recommended 5-day course (as per NICE guidelines) [19] may remain at risk of developing the chronic form of the disease (KS) and, so, is at risk of admission to long-term institutional care.

The purpose of this study was to estimate the long-term cost impact to the public sector in the UK (defined as NHS and social services costs over 35 years) of hospital admissions during which time patients can complete a minimum 5-day course of thiamine treatment, compared with current practice, defined here as 2 days of treatment.

\section{Methods}

A cost model was developed to compare the expected longterm (35 years) costs to the public sector (defined as NHS and social services) of different IV thiamine replacement admission strategies: 2 vs 5 vs 10 days. The modelled patient population was defined as harmful or dependent drinkers presenting to the ED for any reason, who are malnourished or at risk of malnourishment or who have decompensated liver disease [19]. The base-case scenario 
was of a 30-year-old male, chosen to represent a 'typical' patient (authors' assumption).

\subsection{Systematic Review}

A review of the published literature, using systematic methodology, was conducted on the basis of an adapted version of the Cochrane Drugs and Alcohol Group's search strategy [20]. Relevant terms for the population [e.g. 'Wernicke Encephalopathy' (MeSH), 'Drinking Behaviour' (MeSH)] were crossed with outcome concepts, study type concepts and intervention concepts, as appropriate. The search included MEDLINE ${ }^{\circledR}$ (January 1966 to March 2014) and Embase ${ }^{\circledR}$ (January 1974 to March 2014) databases, as well as the Cochrane Library, and identified 35 potentially useful documents. Hand searching and supporting targeted searches identified an additional five studies. Of these, fulltext versions of 31 articles were requested. The literature review protocol, which includes the full search terms, PRISMA diagram and summary of findings are provided in Electronic Supplementary Material 1 and 2.

Of note was the complete absence of well-conducted randomised controlled trials (RCTs) demonstrating the efficacy of IV thiamine in the prevention and/or treatment of WKS. The only study included in a Cochrane systematic review [21] evaluated the impact of intramuscular thiamine on working memory, 2 days after treatment [22].

The initial draft of the model was reviewed for plausibility, before being populated with existing data and evidence gaps identified. Evidence gaps were bridged using a formal structured elicitation process, the Sheffield Elicitation Framework [23], the results of which are summarized in Electronic Supplementary Material 3 and reported in full elsewhere (manuscript in preparation).

\subsection{Comparator Interventions}

Admission to hospital for 5 days or delayed discharge/transfer to a specific alcohol unit to allow completion of a 5-day treatment course was included as a scenario to ensure compliance with the NICE-recommended IV thiamine replacement strategy [19]. The current standard of care varies between centres and patients; globally, compliance with treatment recommendations appears to be low overall [24-29]. For the purpose of this analysis, therefore, two alternative comparator scenarios were evaluated: a 2-day and a 10-day admission strategy with associated IV thiamine replacement. For example, the 2-day admission scenario may represent a situation in which a patient with suspected WE arrives at the ED with a minor traumatic injury, receives IV thiamine, and is admitted for observation overnight before being discharged the following day.

As per the licensed dose of Pabrinex ${ }^{\circledR}$, treatment of admitted patients was assumed to consist of three pairs of IV thiamine ampoules, administered three times daily for the entire length of admission [17], as well as oral magnesium and multivitamins as detailed below.

\subsection{Model Structure}

A five-state Markov chain model was developed (Fig. 1). This models the prognosis of a simulated patient or cohort of patients by dividing the course of their disease into five discrete states. Patients present to the ED (state 1), with an admission of 2, 5 or 10 days (depending on the scenario being modelled). From state 1 , a patient can either be discharged to the community (state 2), develop KS requiring a community-based care package (state 3),
Fig. 1 Schematic of Markov model. $K S$ Korsakoff's syndrome, LT long-term. Letters a to $e$ refer to sets of parameters as described in the text and Table 1

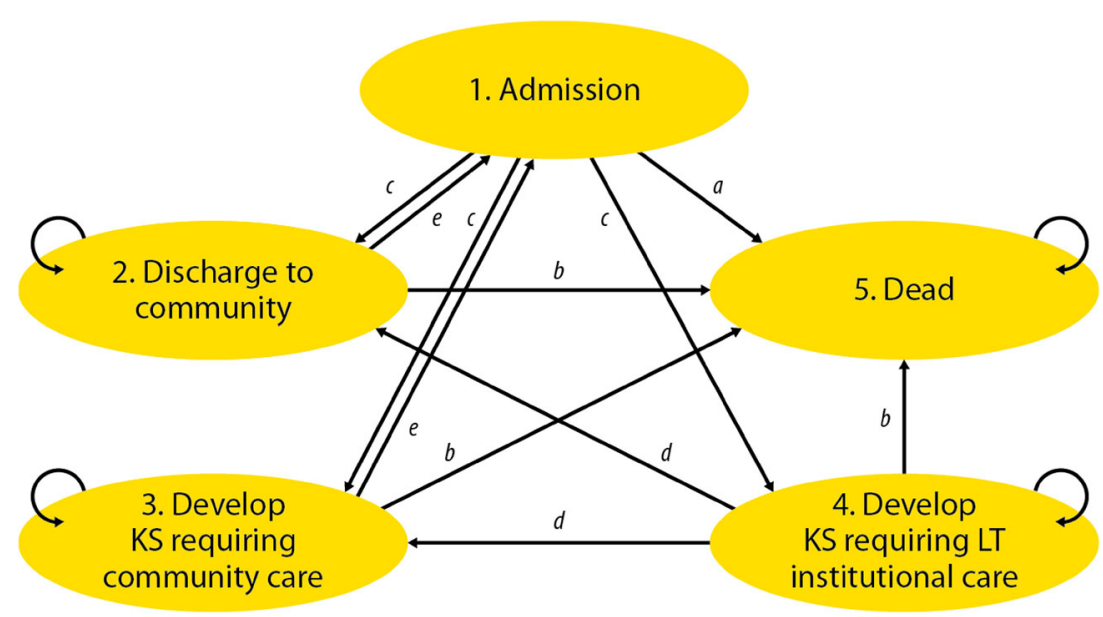


develop KS requiring long-term institutional care (state 4) or die (state 5). The possible transitions from one state to another are represented by the arrows in Fig. 1. Access to long-term institutional care and community-based care was assumed only through an admission from the acute setting (state 1).

The transition period was defined as 3 months, and the probabilities of a transition in each period were based on evidence from the literature and expert opinion, as described below. The 3-month transition period was considered appropriate given the nature of the disease and likely time period for transition between states. A cost was assigned to each state. Totalling the cost of each state multiplied by the time spent in each state, while discounting future costs to present values, provided an estimate of the expected life-time cost of a patient using the base-case (no treatment) scenario. The model was repeated under alternative treatment scenarios of 2, 5 and 10 days with substitution of relevant costs and transition probabilities to allow comparison of the expected long-term costs.

\subsection{Transition Probabilities}

The transitions illustrated in Fig. 1 are grouped (from a-e) and were estimated from a review of the literature, expert opinion (via a formal elicitation panel) and standard NHS databases; a total of nine sources were utilised [16, 30-37]. The key published source for evidence on the natural history of the disease was a 10-year prospective cohort study by Victor and colleagues [16]. The proportion of the target population with WE and the effect of IV thiamine treatment were based on expert elicitation (Electronic Supplementary File 3). The re-presentation rate of patients was based on a study conducted in north-west England [35], and costs were extracted from standard NHS and social services unit costs publications $[36,37]$.

The derivation of each set of transition probabilities labelled a-e in Fig. 1 is fully described in Electronic Supplementary Materials 4 and 5. Briefly, parameter ' $a$ ' relates to acute mortality (within 3 months of presentation), is assumed temporally stationary and is based on data from Victor et al. [16]. Parameter set 'b' relates to longer-term mortality and varies with time (age of simulated patient), drawing on life table data [30], adjusted for the relative risk of all-cause mortality in patients with alcoholism [31, 32]. Parameter set 'c' relates to destination on discharge from acute care, is temporally stationary and is based on data from Victor et al. [16]. Parameter set 'd' relates to partial or complete recovery from $\mathrm{KS}$ and is based on data from Victor et al., with a declining probability of recovery with time since admission (modelled using tunnel states). Finally, parameter set 'e' relates to patient re-presentation at the ED from the community (so-called 'revolving door' patients) and is indirectly informed by a prospective cohort study in England [35].

Expert panel opinion on the probability of response was used to construct a dose-response curve with associated uncertainty. The relative risk of development of $\mathrm{KS}$ by days of treatment was estimated by dividing the probability of response from one treatment dose by the probability of response from another (see Table 1). Details of the elicitation process and associated calculations are provided in Electronic Supplementary File 3. The relative risk of response for 2, 5 and 10 days of treatment was used to adjust parameter set ' $c$ ' in the three comparator scenarios.

\subsection{Cost}

Cost inputs to the model included the cost of the index ED attendance, admission, long-term institutional care and community care packages. The price year of the analysis was 2012/13, with costs incurred after the first year of the analysis discounted at a rate of $3.5 \%$ per annum (the rate recommended by HM Treasury [38] and NICE [39]).

\subsubsection{Index Attendance and Admission}

In 2012/13, the mean cost of an ED attendance was GBP115 [37]. On the first day, following admission, patients were assumed to receive three pairs of IV thiamine ampoules three times daily (GBP1.96 per vial [40]), administered via an IV drip infusion over $30 \mathrm{~min}$ each time [requiring an IV catheter (GBP1.80), giving set (GBP1.95) and saline (GBP0.97)], oral multivitamins (GBP0.05 per day), IV magnesium (GBP1.10 per day), fluid and electrolyte replacement, and monitoring of electrolytes, blood pressure and renal function. Treatment cost on subsequent days was assumed to be identical, except that the catheter was assumed to remain in situ.

The cost was estimated as the total of the ED attendance plus a cost per bed-day and drugs (IV thiamine, multivitamins and magnesium supplements) as described in Table 1. The unit cost of a bed-day was based on the mean cost of excess bed-days (where patients exceed the national tariff trim point) for elective general surgery inpatients for the relevant diagnostic codes. It was, therefore, assumed to include overhead costs and routine nursing activities and monitoring, so no additional cost was assigned for preparing, inserting and monitoring IV drips (although consumables were costed separately).

\subsubsection{Long-Term Institutional and Community Care}

The cost of long-term institutional care for a patient with $\mathrm{KS}$ was estimated at GBP816 per week, or GBP10,608 per 
Table 1 Model inputs

\begin{tabular}{|c|c|c|c|c|c|c|}
\hline Model input & Distribution & $\begin{array}{l}\text { Mean/ } \\
\text { base case }\end{array}$ & SE & $\begin{array}{l}\text { Parameter } \\
1^{\mathrm{a}}\end{array}$ & $\begin{array}{l}\text { Parameter } \\
2^{\mathrm{a}}\end{array}$ & Source/notes \\
\hline $\begin{array}{l}\mathrm{RR} \text { all-cause mortality, chronic alcohol } \\
\text { misuser, male }\end{array}$ & LogNormal & 1.56 & 0.270 & 0.445 & 0.270 & $\begin{array}{l}\text { Rehm et al. [31] used to calculate } \\
\text { LT mortality (transition set b) }\end{array}$ \\
\hline $\begin{array}{l}\mathrm{RR} \text { all-cause mortality, chronic alcohol } \\
\text { misuser, female }\end{array}$ & LogNormal & 2.26 & 0.342 & 0.815 & 0.342 & $\begin{array}{l}\text { Rehm et al. [31] used to calculate } \\
\text { LT mortality (transition set b) }\end{array}$ \\
\hline Prevalence alcohol misuse, male & Constant & $6 \%$ & - & - & - & $\begin{array}{l}\text { Drummond et al. [32] Input to } \\
\text { calculate LT mortality (transition } \\
\text { set b) }\end{array}$ \\
\hline Prevalence alcohol misuse, female & Constant & $2 \%$ & - & - & - & $\begin{array}{l}\text { Drummond et al. [32] Input to } \\
\text { calculate LT mortality (transition } \\
\text { set b) }\end{array}$ \\
\hline $\begin{array}{l}\text { Acute mortality among patients with } \\
\text { WKS }\end{array}$ & Beta & $10.6 \%$ & $1.9 \%$ & 26 & 245 & Input to transition $\mathrm{a}^{\mathrm{b}}$ \\
\hline $\begin{array}{l}\text { Prevalence of WKS in chronic alcohol } \\
\text { misusers attending the ED }\end{array}$ & Scaled beta & $19.0 \%$ & $21.72 \%$ & 2.359 & 1.865 & $\begin{array}{l}\text { Range: } 5,30 \\
\text { Source: expert elicitation } \\
\text { Input to transition set } \mathrm{a}^{\mathrm{b}}\end{array}$ \\
\hline $\begin{array}{l}\text { Proportion of patients presenting at an } \\
\text { ED developing KS, no thiamine }\end{array}$ & Beta & $84.4 \%$ & $2.65 \%$ & 157 & 29 & $\begin{array}{l}\text { Victor et al. [16] } \\
\text { Input to transition set } \mathrm{c}^{\mathrm{b}}\end{array}$ \\
\hline $\begin{array}{l}\text { Proportion of patients with } \mathrm{KS} \text { admitted } \\
\text { to long-term care }\end{array}$ & Beta & $26.0 \%$ & $4.28 \%$ & 27 & 77 & $\begin{array}{l}\text { Victor et al. [16] } \\
\text { Input to transition set } c^{b}\end{array}$ \\
\hline $\begin{array}{l}\text { Probability of recovery from KS and } \\
\text { discharge to community care or } \\
\text { community }\end{array}$ & \multicolumn{5}{|c|}{ (see Electronic Supplementary Material 5) } & Parameter set d \\
\hline $\begin{array}{l}\text { Probability of re-attendance at an ED } \\
\text { once discharged }\end{array}$ & Uniform & $31.6 \%$ & - & $10 \%$ & $50 \%$ & $\begin{array}{l}\text { Assumption based on Pirmohamed } \\
\text { et al. } 2000[35] \\
\text { Transition set } \mathrm{e}^{\mathrm{b}}\end{array}$ \\
\hline $\begin{array}{l}\text { Relative risk of development of } \mathrm{KS} \text {, } \\
10 \text { days of treatment vs } 0\end{array}$ & Normal & 0.050 & 0.013 & 0.050 & 0.013 & Elicitation panel ${ }^{\mathrm{c}}$ \\
\hline 9 days vs 0 & Normal & 0.054 & 0.016 & 0.054 & 0.016 & Elicitation panel ${ }^{\mathrm{c}}$ \\
\hline 8 days vs 0 & Normal & 0.058 & 0.019 & 0.058 & 0.019 & Elicitation panel ${ }^{\mathrm{c}}$ \\
\hline 7 days vs 0 & Normal & 0.061 & 0.022 & 0.061 & 0.022 & Elicitation panel ${ }^{\mathrm{c}}$ \\
\hline 6 days vs 0 & Normal & 0.065 & 0.025 & 0.065 & 0.025 & Elicitation panel ${ }^{\mathrm{c}}$ \\
\hline 5 days vs 0 & Normal & 0.069 & 0.028 & 0.069 & 0.028 & Elicitation panel ${ }^{\mathrm{c}}$ \\
\hline 4 days vs 0 & Normal & 0.281 & 0.073 & 0.281 & 0.073 & Elicitation panel ${ }^{\mathrm{c}}$ \\
\hline 3 days vs 0 & Normal & 0.493 & 0.119 & 0.493 & 0.119 & Elicitation panel ${ }^{\mathrm{c}}$ \\
\hline 2 days vs 0 & Normal & 0.705 & 0.165 & 0.705 & 0.165 & Elicitation panel ${ }^{\mathrm{c}}$ \\
\hline 1 day vs 0 & Normal & 0.852 & 0.148 & 0.852 & 0.148 & Elicitation panel ${ }^{\mathrm{c}}$ \\
\hline Cost of ED attendance (GBP) & Gamma & 115 & 28.20 & 16.4681 & 6.9489 & NHS Reference Costs 2013 [37] \\
\hline $\begin{array}{l}\text { Cost of long-term institutional care, per } \\
3 \text { months (GBP) }\end{array}$ & Uniform & 10,608 & - & 8000 & 12,000 & PSSRU [36] \\
\hline $\begin{array}{l}\text { Cost of community care per } 3 \text { months } \\
\text { (GBP) }\end{array}$ & Uniform & 5941 & - & 2500 & 6500 & PSSRU [36] \\
\hline Cost of inpatient bed-day (GBP) & Gamma & 279 & 43.03 & 42.0417 & 6.6363 & NHS Reference Costs $2013[37]^{\mathrm{d}}$ \\
\hline $\begin{array}{l}\text { Thiamine preparation, per pair of } \\
\text { ampoules }\end{array}$ & Constant & GBP1.96 & - & & & BNF $67[40]^{\mathrm{e}}$ \\
\hline Multivitamins, per day & Constant & GBP0.054 & - & & & BNF $67[40]^{\mathrm{f}}$ \\
\hline Magnesium supplement, per day & Constant & GBP1.10 & - & & & BNF $67[40]^{\mathrm{g}}$ \\
\hline IV giving set & Constant & GBP1.95 & - & & & Representative cost $^{\mathrm{h}}$ \\
\hline Saline $1 \mathrm{~L}$ & Constant & GBP0.97 & - & & & BNF $67[40]^{\mathrm{i}}$ \\
\hline
\end{tabular}


Table 1 continued



3-month period (13 weeks). This value was based on the cost of caring for a person with mental health problems in a local authority care home [36]. The cost of community care was estimated at GBP457 per week or GBP5941 per 3 -month period. This value was based on the mean cost of a social care support package for people with mental health problems [36].

\subsection{Analytic Approach}

\subsubsection{Base Case}

The analysis compared three scenarios: 2-, 5- and 10-day admissions for administration of IV thiamine in a 30-yearold male. Analysis was based around Monte Carlo simulation of model inputs: probability distributions were assigned to model input parameters as shown in Table 1. These distributions were sampled repeatedly (1000 times) and the cost for each scenario was recorded. The mean and the 2.5th and 97.5th centiles of the cost under each scenario were interpreted as the expected cost and $95 \%$ confidence interval (CI). One thousand iterations were confirmed as sufficient to achieve stability of results by repeatedly running sets of simulations and comparing the results.

\subsubsection{Sensitivity Analysis}

One-way sensitivity analysis was also undertaken, comparing 2- vs 5-day admissions, varying model inputs individually between plausible ranges. The values, at which a 5-day admission would become more costly than a 2-day admission, where these exist, were identified in a threshold analysis.

\subsubsection{Budget Impact Analysis}

The predicted budget impact for health and social services relating to a representative ED unit with 500 patients presenting per annum, increasing by 10 patients each year, was estimated. This is intended to represent a 'typical' ED with one or two patients presenting each day (authors' assumption).

\section{Results}

\subsection{Base Case}

The expected cost of care over 35 years following the admission for 2 days of a harmful or dependent drinker presenting to the ED, who is malnourished or at risk of malnourishment or has decompensated liver disease and in whom WE cannot be excluded, is approximately GBP123,700 (present value, discounted at 3.5\%; $95 \%$ CI GBP50,000-GBP221,300, Table 2). Of this cost, approximately GBP730 is the cost of the index ED attendance and admission. The cost of repeat attendances to the ED over the following 35 years totals approximately GBP8700. The expected cost of long-term care is approximately GBP114,300, of which GBP96,700 is accounted for by long-stay institutional care, the remainder being community-based care.

If the patient is admitted for an extra 3 days (5-day admission) to receive a longer course of IV thiamine plus associated care, the cost of the index attendance and admission rises to approximately GBP1700. The expected cost of future attendances to the ED and admissions 
Table 2 Expected cost of admission and long-term care costs (present values, discounted at $3.5 \%$ )

\begin{tabular}{lccccr}
\hline $\begin{array}{l}\text { Days of } \\
\text { treatment }\end{array}$ & $\begin{array}{l}\text { Cost (GBP) of } \\
\text { index admission }\end{array}$ & $\begin{array}{l}\text { Cost (GBP) of } \\
\text { future admissions }\end{array}$ & $\begin{array}{l}\text { Long-term community } \\
\text { care costs (GBP) }\end{array}$ & $\begin{array}{l}\text { Long-term institutional } \\
\text { care costs (GBP) }\end{array}$ & Total cost (GBP) (95 \% CI) \\
\hline 2 & 732 & 8688 & 17,604 & 96,677 & $123,701(50,047$ to 221,276) \\
5 & 1651 & 22,342 & 1958 & 10,778 & $36,729(18,245$ to 58,165$)$ \\
10 & 3184 & 43,263 & 1421 & 7864 & $55,733(29,995$ to 84,224$)$ \\
$2-5^{\text {a }}$ & & & & $83,722(19,279$ to 172,326$)$ \\
$5-10^{\text {a }}$ & & & & $-19,187(-37,165$ to -4486$)$ \\
$2-10^{\text {a }}$ & & & & $64,535(-1,007$ to 151,594$)$ \\
\hline
\end{tabular}

a Increment: e.g. cost of 2 days minus 5; positive indicates a saving, negative indicates increase in cost

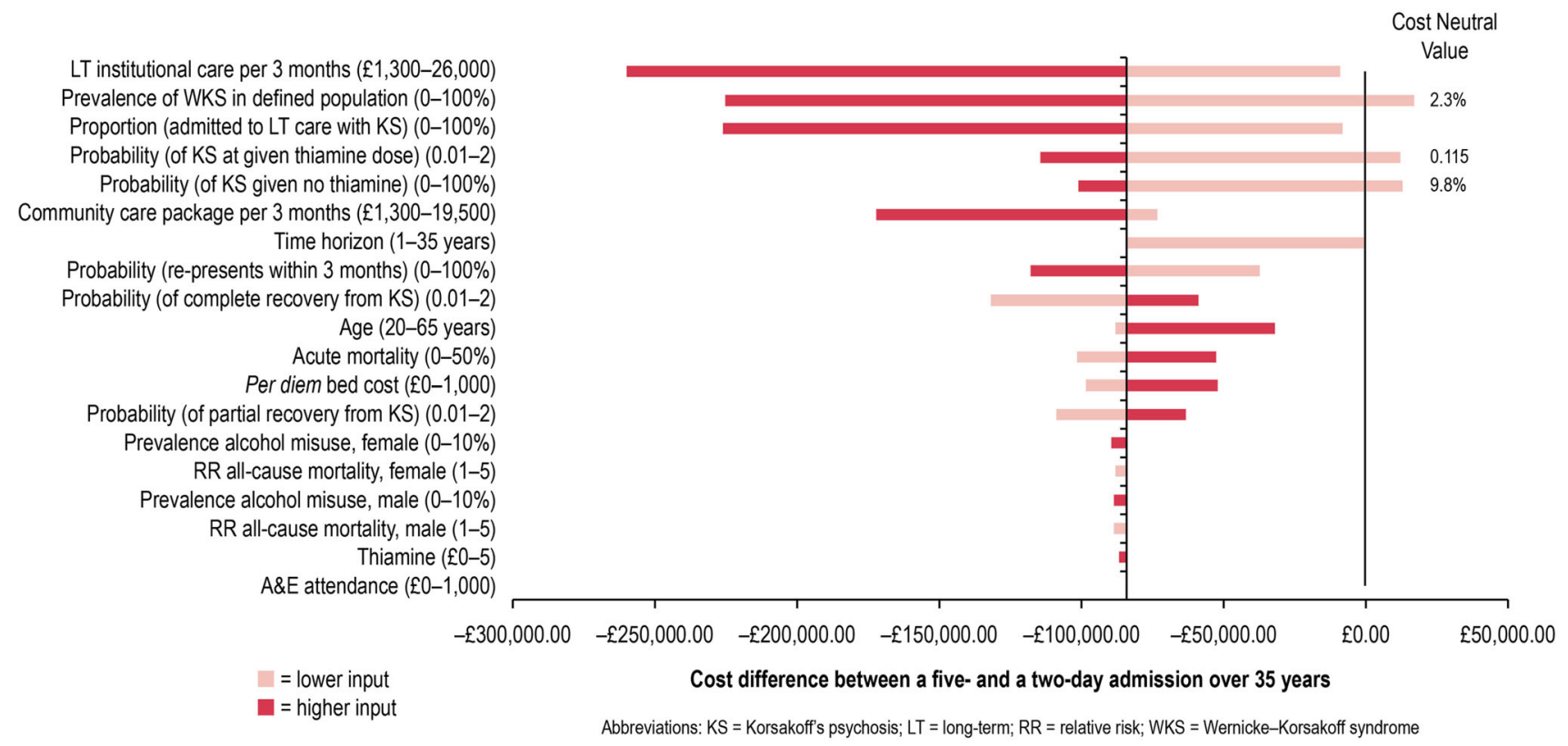

Fig. 2 Tornado diagram comparing cost difference between 2- and 5-day admissions when individual parameters are varied between the ranges described. A table of these results is in Electronic Supplementary File 6

is also higher at GBP22,300. This increase in future readmissions is due to the higher proportion of patients being discharged to the community, where they are at risk of readmission, and a lower proportion of patients being admitted to long-term care, where they are not. Due to the expected reduction in cases of KS from the longer course of thiamine, the total expected cost of long-term care is reduced to GBP12,700, yielding a total expected cost over 35 years of GBP36,700 (95\% CI GBP18,245 to GBP58,165).

Extending the admission by a further 5 days (10-day admission) increases the cost of the index admission to GBP3200. This is expected to reduce the risk of KS further, leading to a greater proportion of the patient population being discharged to the community (where they are at risk of readmission). The combination of the greater length of stay and increased proportion at risk of readmission means that the expected cost of future ED attendances and admissions is GBP43,300. However, the expected lower risk of KS means the cost of long-term institutional and community care totals GBP9300, yielding an expected cost over 35 years of GBP55,700 (95\% CI GBP29,995 to GBP84,224). This is higher than the expected cost from a 5-day admission: the extra cost of the longer admission exceeds the cost savings from the reduced admissions to long-term care (Table 2).

\subsection{Sensitivity and Threshold Analyses}

Threshold analysis comparing the cost difference between 2 and 5 days' treatment suggests that the results are robust to uncertainty in all model parameters, except for the prevalence of WKS among patients presenting to the ED, the probability of developing $\mathrm{KS}$ with no thiamine treatment and the dose-response relationship to IV thiamine (Fig. 2; Electronic Supplementary Material 6). The values 
at which a 5-day admission period becomes more expensive than a 2-day admission are, however, at some distance from the base-case assumptions (of note is that all three of these parameters are based on expert opinion rather than experimental evidence); for example, a 5-day admission fails to become cost saving compared with a 2-day admission only when the prevalence of WKS in the modelled population presenting to the ED falls below $2.25 \%$. The base-case value is $19 \%$. Similarly, the 5-day admission ceases to be cost saving when the probability of developing KS without treatment is $10 \%$ or less (base-case value $84.4 \%$ ). Finally, only if IV thiamine is more than eight times as effective at preventing KS than predicted by the expert panel does the 5-day admission become more expensive than a 2-day admission (i.e. when the dose-response curve is shifted such that the probability of developing KS for a given dose of thiamine is only 0.12 times that estimated by our expert panel, thus a 2-day course prevents most cases of KS and the added benefit of the extra 3 days is minimal).

\subsection{Budget Impact}

The figures presented above estimate the total cost per patient presenting to the ED meeting the characteristics of the population described in the methods. For the purpose of calculating the potential budget impact of changing IV thiamine replacement services, the following scenario, defined by the authors to represent a 'typical' ED was evaluated:

- Population a typical major ED unit seeing 500 unique patients per annum, with 10 new patients joining the prevalent population each year.

- Current policy to treat $75 \%$ of patients with 2 days of IV thiamine and $25 \%$ of patients with 5 days of IV thiamine.

- Proposed policy to treat $100 \%$ of patients with 5 days of IV thiamine.

Under the current policy, defined above, the present value of expenditure on ED attendance and long-term care for the prevalent cohort plus the incident cases over the next 35 years is expected to be GBP64.1 million. Changing the policy so that $100 \%$ of patients receive 5 days of IV thiamine treatment would be expected to reduce the value of expenditure to GBP23.6 million, a GBP40.6 million reduction (95\% CI GBP10.3 million to GBP82.4 million); that is, an average reduction of GBP1.2 million per annum (95\% CI GBP0.3 million to GBP2.3 million). The impact on a specific ED would depend on the number of patients presenting each year and the current treatment policies.

\section{Discussion}

Under the assumptions of this model, admitting or delaying the discharge of patients considered at risk of WE increases expected acute care costs, but is expected to result in a substantial overall reduction in life-time costs to the public sector (defined as NHS and social services and over a 35-year time horizon). This expected reduction is due to the expected reduced risk of developing $\mathrm{KS}$ and, hence, the requirement for admission to either a long-term institutional facility or provision of a community-based care package. The expected lifetime cost to the public sector for admitting a patient for 2 days is GBP123,700. Extending the admission to allow 5 days of IV thiamine replacement increases the acute care cost; however, owing to the expected reduction in risk of $\mathrm{KS}$, the expected life-time cost falls to GBP36,700: a total $70 \%$ reduction in costs incurred.

\subsection{Implications for Practice}

The assumption in this model is that patients can be accommodated in the acute sector for an extended admission. Existing pressures on the acute sector may preclude this in the short term. This analysis shows, however, that prolonging admission by a few days has the possibility to ease the long-term financial burden of these patients on the public sector quite substantially. These results could, therefore, be used as an input to a business case to explore options for accommodating these patients or, at a minimum, to investigate approaches by which the NHS can trace patients for the subsequent few days post-discharge to deliver the IV thiamine. The implications of this analysis are that savings to the social care budget may be achieved by increasing cost to the NHS budget. This suggests the two organisations would need to co-operate in order to realise the net public sector savings, a need recognised at a more aggregate level too [41].

\subsection{Strengths and Weaknesses}

At the time of study completion, there were no reports of any other analyses attempting to quantify the cost impact of extending the admission of patients at risk of WKS to ensure completion of a course of IV thiamine replacement therapy.

The analysis is based on a relatively simple decision model and presented in a manner that allows others to replicate the work. Assumptions made in the model (for example, the proportion of patients admitted to long-term care) were conservative in that they would tend to 
underestimate any cost savings associated with reduced rates of admission to long-term facilities.

It must be noted that this analysis focuses only on NHS and social services costs. We do not explicitly measure and value any health gains associated with the prevention of KS or consider any broader social or emotional costs. The impact of alcohol abuse is not only on the individual, but extends to their family and society as a whole. Our estimate is, therefore, an underestimate of the societal cost of reducing the prevalence of KS. In 2003, the UK government estimated the societal cost of alcohol misuse at between GBP18 billion and GBP20 billion [42]. It is plausible that a holistic strategy could reduce part of this burden, one component of which should be ensuring that patients who present to an ED receive sufficient thiamine replacement where appropriate.

This analysis has a number of other limitations. First, the entire area of IV thiamine replacement therapy in this patient population is very under-researched. In particular, no RCTs that demonstrate the efficacy or effectiveness of IV thiamine replacement therapy are available, and the optimum length of treatment is unknown. In the absence of such experimental data, the relationship between length of treatment and risk of developing KS was elicited from an expert panel, using an established method [23], which focuses on quantifying the uncertainty around experts' beliefs (see Electronic Supplementary Material 3). Thus, the model does not incorporate data on the dose-response relationship, but rather the beliefs of experts as to the doseresponse relationship. In the absence of good-quality RCTs or prospective cohort data, this approach is the next best alternative. It should be noted that conducting such a prospective RCT or cohort study would provide a much firmer evidence base to incorporate into this model, but would be extremely challenging due to the nature of the patient group. However, our sensitivity analysis suggests that a 2-day course of thiamine would have to be much more effective at preventing $\mathrm{KS}$ as believed by our experts to alter the conclusion of this study. This model relies largely on the study completed by Victor and colleagues [16], who succeeded in following up a cohort of 245 patients presenting with WE at their centres. Just over 100 of these patients were followed for up to 10 years; however, this study was conducted in the 1950s and 1960s.

Secondly, we chose a somewhat arbitrary 35 -year time horizon. This was intended to capture the majority of the remaining lifespan of individuals in the model. Arguably a longer time span would capture more costs of relevance, but after discounting, the impact on present values will be minimal. Furthermore, a shorter time horizon will underestimate future avoided costs, thus our analysis further underestimates the true life-time net cost impact of the longer acute admissions.
Finally, the model also may be considered conservative since the same probability of repeat presentation to an ED setting was applied to all scenarios of treatment duration in the model. This was necessary because the potential correlation between length of treatment and subsequent rate of repeat presentation to the ED could not be robustly ascertained from the available Hospital Episode Statistics and prescription data and the range of possible International Classification of Diseases (ICD) codes used to describe the modelled population. It is, however, postulated that an increased length of admission would reduce rates of representation, as patients receiving optimal dosing with IV thiamine during their hospital stay might become better informed about their condition and the potential consequences of harmful drinking. It is also plausible that improved cognitive functioning might allow them to engage more effectively with healthcare professionals, thereby improving their understanding of the condition and their own decision making.

\section{Conclusion}

Admitting or delaying the discharge of patients presenting to the ED until a minimum 5-day dose of IV thiamine can be administered has the potential to save the public sector substantial amounts of money over the longer term; for example, extending the admission of a patient from 2 to 5 days for the purpose of IV thiamine replacement could save the public sector GBP87,000 per patient over 35 years (present value, discounted at $3.5 \%$ ). The model showed that every extra GBP1 spent in acute care to manage WE is estimated to save GBP6 in future social service costs.

Given perennial pressures on hospital beds, options should be explored, whereby IV thiamine replacement therapy can be delivered to these patients for the recommended minimum 5-day dose either within an inpatient, outpatient or community setting. While our analysis considers only extending admissions within a general ward, the cost implications of other approaches, such as specific wards or units, should be carefully considered and this analysis should form a useful part of the business case for such an investment.

Acknowledgments This study was funded by Archimedes UK Pharma Ltd, the manufacturer of Pabrinex ${ }^{\circledR}$. In July 2014, ProStrakan Group plc acquired Archimedes Pharma UK Ltd. Hayward Medical Communications provided editorial and writing support during manuscript development.

\section{Compliance with Ethical Standards}

Conflict of interest statement At time of analysis, GS was an employee of Archimedes UK Pharma Ltd. EW received an honorarium from Archimedes UK Pharma Ltd to undertake this analysis. ZM 
was a member of the elicitation panel used to support the development of the model, but received no honorarium for this contribution.

Author contributions EW developed the model, ran the analyses and interpreted the results. GS assisted in the conception and design of the study. ZM contributed to the background and interpretation of results. All authors were involved in drafting and critically revising the manuscript.

Open Access This article is distributed under the terms of the Creative Commons Attribution-NonCommercial 4.0 International License (http://creativecommons.org/licenses/by-nc/4.0/), which permits any noncommercial use, distribution, and reproduction in any medium, provided you give appropriate credit to the original author(s) and the source, provide a link to the Creative Commons license, and indicate if changes were made.

\section{References}

1. Thomson AD, Cook CCH, Touquet R, Henry JA. The Royal College of physicians report on alcohol: Guidelines for managing Wernicke's encephalopathy in the accident and emergency department. Alcohol Alcohol. 2002;37(6):513-21 (PubMed PMID: 2002430132. English).

2. Harper C, Fornes P, Duyckaerts C, Lecomte D, Hauw JJ. An international perspective on the prevalence of the WernickeKorsakoff syndrome. Metabolic brain disease. 1995;10(1):17-24 (PubMed PMID: 7596325. Epub 1995/03/01. Eng).

3. Harper C, Gold J, Rodriguez M, Perdices M. The prevalence of the Wernicke-Korsakoff syndrome in Sydney, Australia: a prospective necropsy study. J Neurol Neurosurg Psychiatry. 1989;52(2):282-5 (PubMed PMID: 2784828. Pubmed Central PMCID: PMC1032524. Epub 1989/02/01. Eng).

4. Harper CG, Sheedy DL, Lara AI, Garrick TM, Hilton JM, Raisanen J. Prevalence of Wernicke-Korsakoff syndrome in Australia: has thiamine fortification made a difference? Med J Aust. 1998;168(11):542-5 (PubMed PMID: 9640303. Pubmed Central PMCID: Pmc3391549. Epub 1998/06/26. Eng).

5. Skullerud K, Andersen SN, Lundevall J. Cerebral lesions and causes of death in male alcoholics. A forensic autopsy study. Int J Legal Med. 1991;104(4):209-13 (PubMed PMID: 1931737. Epub 1991/01/01. Eng).

6. Cook CC, Hallwood PM, Thomson AD. B Vitamin deficiency and neuropsychiatric syndromes in alcohol misuse. Alcohol Alcohol (Oxf, Oxfs). 1998;33(4):317-36 (PubMed PMID: 9719389).

7. Cook CC. Prevention and treatment of Wernicke-Korsakoff syndrome. Alcohol Alcohol (Oxf, Oxfs) Suppl. 2000;35(1):19-20 (PubMed PMID: 11304070. Epub 2001/04/17. Eng).

8. Kopelman MD, Thomson AD, Guerrini I, Marshall EJ. The Korsakoff syndrome: clinical aspects, psychology and treatment. Alcohol Alcohol (Oxf, Oxfs). 2009;44(2):148-54 (PubMed PMID: 19151162. Epub 2009/01/20. Eng).

9. Sechi G, Serra A. Wernicke's encephalopathy: new clinical settings and recent advances in diagnosis and management. Lancet Neurol. 2007;6(5):442-55 (PubMed PMID: 17434099. Epub 2007/04/17. Eng).

10. Thomson AD, Guerrini I, Marshall EJ. The evolution and treatment of Korsakoff's syndrome: out of sight, out of mind? Neuropsychol Rev. 2012;22(2):81-92 (PubMed PMID: 22569770. Pubmed Central PMCID: PMC3545191. Epub 2012/05/10. Eng).
11. Thomson AD, Cook CCH, Guerrini I, Sheedy D, Harper C, Marshall EJ. Wernicke's encephalopathy: 'Plus ca change, plus c'est la meme chose'. Alcohol Alcohol. 2008;43(2):180-6 (PubMed PMID: 2008166133. English).

12. Paton A, Touquet R. ABC of alcohol. 4th ed. Malden: Blackwell Publishing; 2005.

13. Harper CG, Giles M, Finlay-Jones R. Clinical signs in the Wernicke-Korsakoff complex: a retrospective analysis of 131 cases diagnosed at necropsy. J Neurol Neurosurg Psychiatry. 1986;49(4):341-5 (PubMed PMID: 3701343. Pubmed Central PMCID: 1028756. Epub 1986/04/01. Eng).

14. Naidoo DP, Bramdev A, Cooper K. Wernicke's encephalopathy and alcohol-related disease. Postgrad Med J. 1991;67:978-81.

15. Touquet R, Brown A. Alcohol misuse: positive response. Alcohol Health Work for every acute hospital saves money and reduces repeat attendances. EMA-Emergency Medicine Australasia. 2006;18(2): 103-7 (PubMed PMID: 2006170524. English).

16. Victor M, Adams RD, Collins GH. The Wernicke-Korsakoff syndrome and related neurologic disorders due to alcoholism and malnutrition. 2nd ed. Philadelphia: F.A. Davis Co.; 1989.

17. Agro K, Blackhouse G, Goeree R, Willan AR, Huang JQ, Hunt $\mathrm{RH}$, et al. Cost effectiveness in Canada of a multidrug prepackaged regimen $(\mathrm{Hp}-\mathrm{PAC})+$ for Helicobacter pylori eradication. Pharmacoeconomics. 2001;19(8):831-43 (PubMed PMID: 11596835. Epub 2001/10/13. Eng).

18. Joint Formulary Committee. British National Formulary. 67th ed. London: BMJ Group and Pharmaceutical Press; 2014.

19. National Institute for Health and Care Excellence. Alcohol-use disorders: diagnosis and clinical management of alcohol-related physical complications. London: NICE; 2010.

20. Amato L, Davoli M, Ali R, F. F, Farrell M, Foxcroft D, Cochrane Drugs and Alcohol Group, et al. About the Cochrane Collaboration (Cochrane Review Groups (CRGs) 2014, Issue 10 [10 November 2014]). Available from: http://onlinelibrary.wiley. com/o/cochrane/clabout/articles/ADDICTN/frame.html. Last accessed 7 Nov 2015.

21. Day E, Bentham PW, Callaghan R, Kuruvilla T, George S. Thiamine for prevention and treatment of Wernicke-Korsakoff Syndrome in people who abuse alcohol. Cochrane Database Syst Rev. 2013;7:CD004033 (PubMed PMID: 23818100. Epub 2013/07/03. Eng).

22. Ambrose ML, Bowden SC, Whelan G. Thiamin treatment and working memory function of alcohol-dependent people: preliminary findings. Alcohol Clin Exp Res. 2001;25(1):112-6.

23. Oakley JE, O'Hagan A. SHELF: The Sheffield Elicitation Framework (version 2.0) Sheffield, UK2010. 2014. Available from: http://tonyohagan.co.uk/shelf. Last accessed 7 Nov 2015

24. Benaouda F. The prophylactic use of Pabrinex during alcohol detoxification treatment. Clinical Pharmacist. 2011;3(3):S2 (PubMed PMID: 70749560. English).

25. Ferguson RK, Soryal IN, Pentland B. Wernicke-Korsakoff syndrome in head injury: a missed insult. Alcohol and alcoholism (Oxford, Oxfordshire) Supplement. 2000;35(1):16-8 (PubMed PMID: 11304069. Epub 2001/04/17. Eng).

26. Isenberg-Grzeda E, Chabon B, Nicolson SE. Prescribing thiamine to inpatients with alcohol use disorders: how well are we doing? Journal of addiction medicine. 2014;8(1):1-5 (PubMed PMID: 24343128. Epub 2013/12/18. Eng).

27. Thomson AD, Cook CC. Parenteral thiamine and Wernicke's encephalopathy: the balance of risks and perception of concern. Alcohol Alcohol (Oxf, Oxfs). 1997;32(3):207-9 (PubMed PMID: 9199720. Epub 1997/05/01. Eng).

28. Ferguson RK, Soryal IN, Pentland B. Thiamine deficiency in head injury: a missed insult? Alcohol Alcohol (Oxf, Oxfs). 1997;32(4): 493-500 (PubMed PMID: 9269857. Epub 1997/07/01. Eng). 
29. Hope LC, Cook CC, Thomson AD. A survey of the current clinical practice of psychiatrists and accident and emergency specialists in the United Kingdom concerning vitamin supplementation for chronic alcohol misusers. Alcohol Alcohol (Oxf, Oxfs). 1999;34(6):862-7 (PubMed PMID: 10659721).

30. Office for National Statistics. Interim Life tables for England 1980-82 to 2010-12. Webpage. http://www.ons.gov.uk/ons/rel/ lifetables/interim-life-tables/2010-2012/rft-england.xls. Last accessed 7 Nov 2015.

31. Rehm J, Greenfield TK, Rogers JD. Average volume of alcohol consumption, patterns of drinking, and all-cause mortality: results from the US National Alcohol Survey. Am J Epidemiol. 2001;153(1):64-71.

32. Drummond C, Oyefeso A, Phillips T, Cheeta S, Deluca P, Perryman $\mathrm{K}$, et al. The 2004 national alcohol needs assessment for England. London: Department of Health; 2004.

33. Pharoah PD, Hollingworth W. Cost effectiveness of lowering cholesterol concentration with statins in patients with and without preexisting coronary heart disease: life table method applied to health authority population. BMJ. 1996;312(7044):1443-8 (PubMed PMID: 8664620. Pubmed Central PMCID: 2351181).

34. Gray A, Clarke P, Wolstenholme J, Wordsworth S. Applied methods of cost-effectiveness analysis in health care. In: Gray A, Briggs A, editors. Oxford: Oxford University Press; 2011.
35. Pirmohamed M, Brown C, Owens L, Luke C, Gilmore IT, Breckenridge AM, et al. The burden of alcohol misuse on an inner-city general hospital. QJM. 2000;93(5):291-5.

36. Curtis L. Unit Costs of Health and Social Care 2013. Canterbury: University of Kent at Canterbury; 2014.

37. Department of Health. National Schedule of Reference Costs 2012-13. London. https://www.gov.uk/government/uploads/ system/uploads/attachment_data/file/260405/2012-13_national_ schedule_of_reference_costs.xls. Last accessed 7 Nov 2015.

38. Treasury HM. The green book: appraisal and evaluation in Central Government. London: HM Treasury; 2003.

39. National Institute for Health and Care Excellence. Guide to the Methods of Technology Appraisal 2013. London. http://www.nice. org.uk/article/pmg9/chapter/Foreword. Last accessed: 7 Nov 2015.

40. Metvix $160 \mathrm{mg} / \mathrm{g}$ cream summary of product characteristics 2007. Available from: http://emc.medicines.org.uk/emc/assets/c/ html/DisplayDoc.asp?DocumentID=11913. Cited 30 Oct 2007.

41. The King's Fund. A new settlement for health and social care. London: The King's Fund; 2014.

42. Cabinet Office Strategy Unit. Alcohol misuse: how much does it cost? London: HMSO (Her Majesty's Stationery Office); 2003. 